\title{
Intercoronary collateral flow detected by Doppler colour flow mapping is an additional diagnostic sign in children with anomalous origin of the left coronary artery from the pulmonary artery
}

Department of Paediatric Cardiology, University of Vienna, Austria

U Salzer-Muhar

E Proll

Department of Internal Medicine,

A.Ö. Krankenhaus

Krems, Austria

G Kronik

Correspondence to Dr Ulrike Salzer-Muhar, Dept. für Pädiatrische Kardiologie, Universitäts kinderklinik Wien, Waehringer Guertel 18-20, Waehringer Guertel 18-20
A-1090 Vienna, Austria
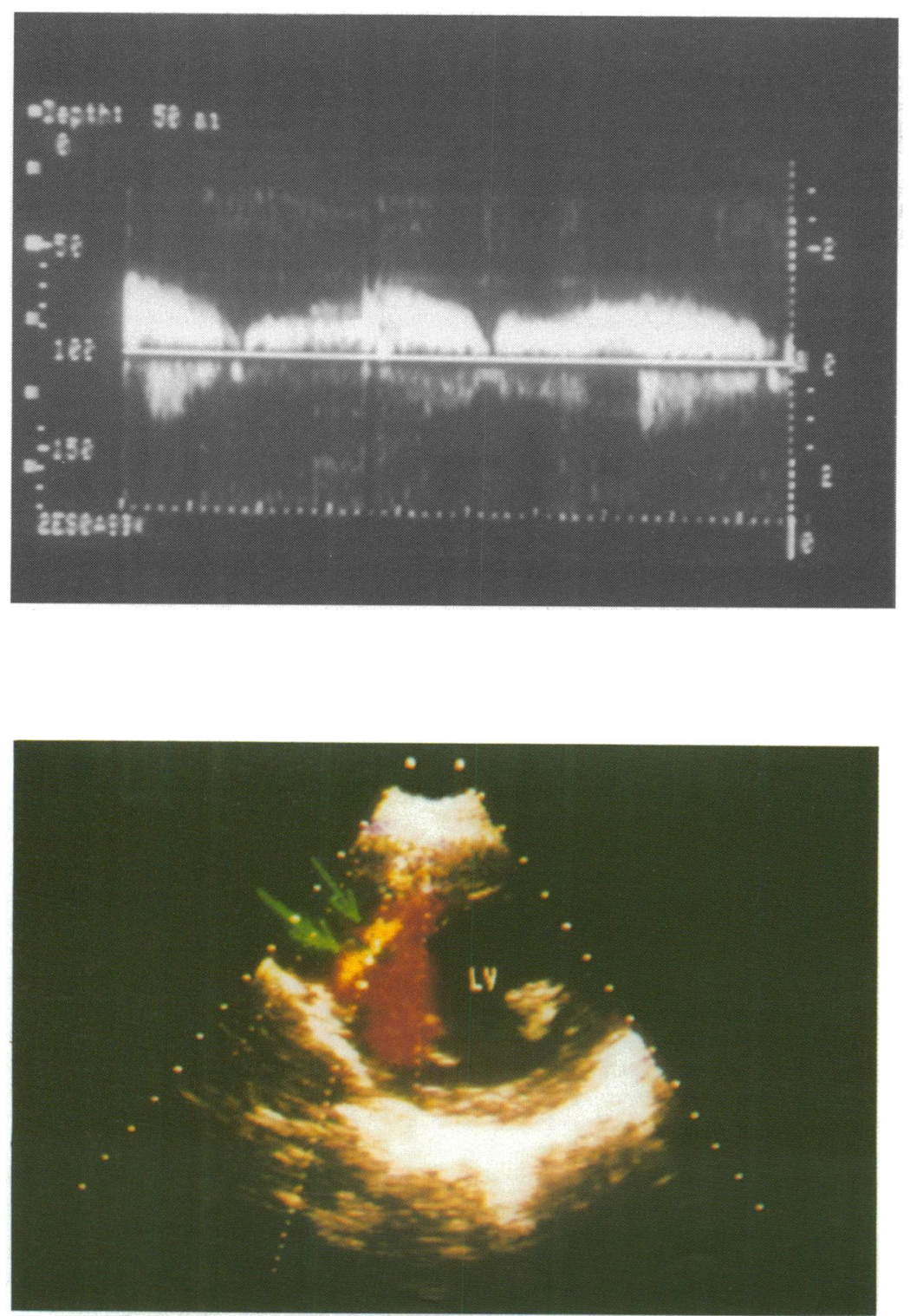

Figure 1 (Top) Parasternal short axis view of the left ventricle in patient 1. Colour flow mapping shows aliasing in the ventricular septum caused by the circular course of a septal collateral. (Bottom) Pulsed Doppler echocardiography shows a continuous flow profile in collateral. (Bottom)
the collateral artery.

\begin{abstract}
Intercoronary collateral flow within septal collaterals was detected by colourcoded Doppler echocardiography in three children with anomalous origin of the left coronary artery from the pulmonary artery. In each of the three patients angiography confirmed the presence of septal collaterals.
\end{abstract}

(Br Heart f 1993;70:558-559)

2. aspect of the pulmonary artery-colour flow mapping showed collateral flow within septal intercoronary branches.

\section{Case reports}

Patient 1 a 10 year old girl, presented with a murmur, moderate cardiomegaly on the chest $x$ ray, and a normal electrocardiogram. Cross sectional echocardiography showed a normokinetic left ventricle with normal diameters, mitral valve prolapse with mild mitral regurgitation, and ALCAPA. Both the right and left coronary artery were enlarged: there was a broad jet with a systolic and diastolic left to right shunt over the LCA into the pulmonary artery. When scanning the ventricular septum at the level of the papillary muscles in the short axis we noticed continuous turbulent flow with a maximal velocity of $1 \mathrm{~m} / \mathrm{s}$ which was interpreted as septal collateral flow (fig 1).

Patient 2, a 2-month-old boy, presented with congestive heart failure, cardiomegaly, and ST changes and negative $T$ waves in the left precordial leads. He had a poorly contracting dilated left ventricle (shortening fraction $8 \%$ ) with signs of endocardial fibroelastosis. Colour flow mapping showed evidence of only a tiny jet with a systolic and diastolic retrograde flow from the LCA into 

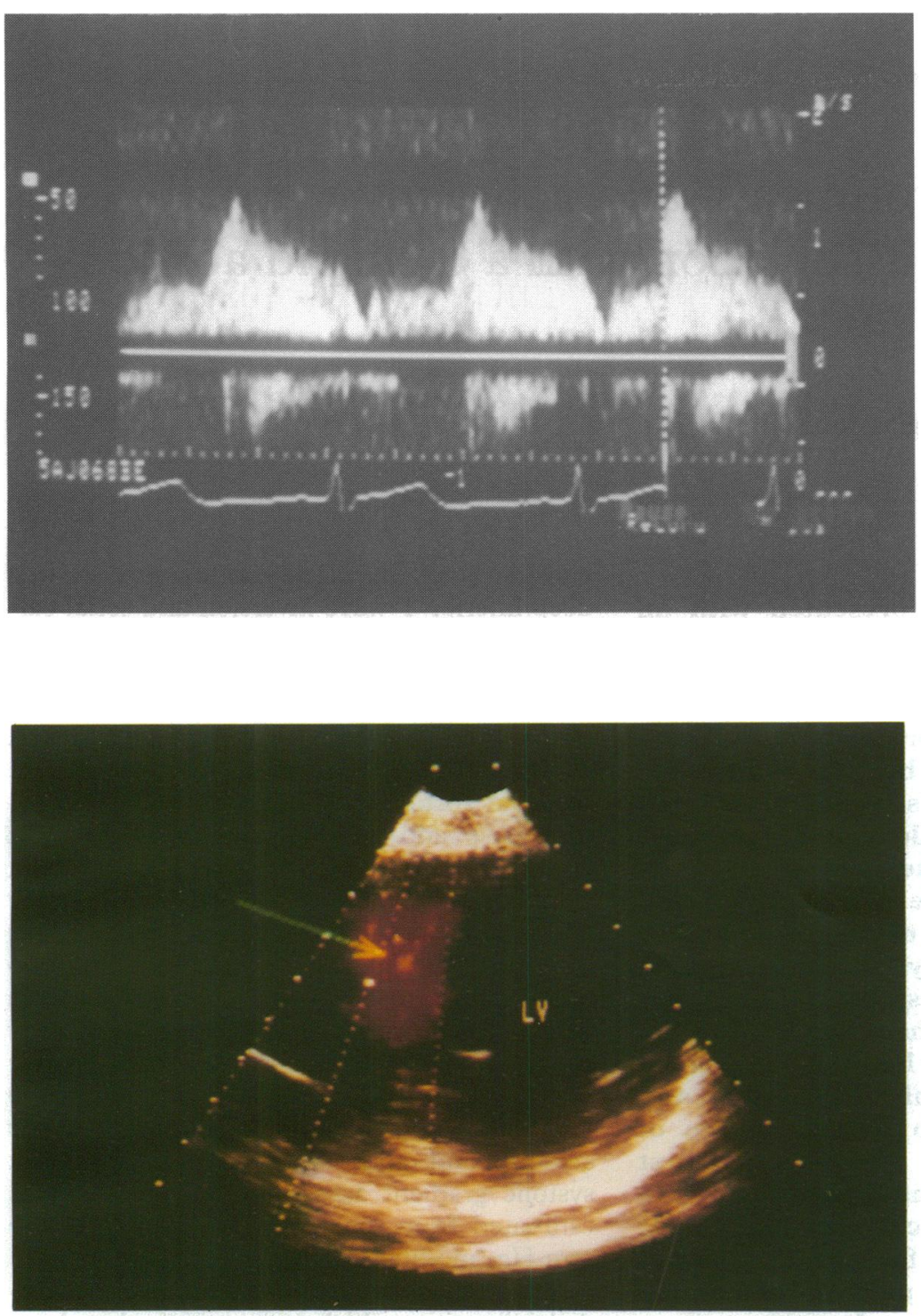

Figure 2 (Upper) Parasternal short axis view of the left ventricle in patient 2. Colour flow mapping shows aliasing in the ventricular septum caused by the circular course of a septal collateral. (Lower) Pulsed Doppler echocardiography shows a systolic-diastolic flow profile within the collateral artery.

the pulmonary artery. There was also evidence of a septal collateral flow with a maximal velocity of $1 \mathrm{~m} / \mathrm{s}$ in early diastole.

Patient 3, a 4-year-old boy, had a heart murmur suggestive of mitral regurgitation, moderate cardiomegaly on the chest $x$ ray and deep $Q$ in $I, a V L$, and the left precordial leads. Cross sectional echocardiography showed a mildly dilated left ventricle with signs of endocardial fibroelastosis of the mitral valve and the papillary muscles as well as of parts of the left ventricular posterior wall. There was moderate mitral regurgitation. Colour flow mapping showed a broad jet with a systolic and diastolic shunt from the LCA into the pulmonary artery. Again there was systolic and diastolic collateral septal flow with a maximum velocity of $1 \mathrm{~m} / \mathrm{s}$ in early diastole (fig 2).

In all three patients angiography confirmed the presence of septal collaterals and ALCAPA. Aortic implantation of the LCA was performed in patients 2 and 3. Patient 1 was given an internal mammary artery anastomosis.
Postoperative follow up colour flow mapping demonstrated a decrease in the septal collateral flow in all three patients.

\section{Discussion}

The combined use of cross sectional, pulsed, and colour Doppler echocardiographic examination has been shown to increase the ability to detect ALCAPA. ${ }^{2}$ The rate of false negative diagnosis based on cross sectional echocardiography alone may be as high as $50 \%{ }^{5}$ This is because limitations of lateral resolution can create an artefact that indicates that the coronary artery arises from the aortic root. For this reason a modified high left parasternal short axis view was recommended to demonstrate the direct continuity of the LCA from the pulmonary trunk. ${ }^{4}$ Colour flow mapping has been found to be superior to pulsed Doppler for detecting the retrograde flow in the pulmonary trunk ${ }^{4}$ and the left coronary artery. ${ }^{3}$ Only recently a retrograde flow in at least two segments of the left coronary artery system was reported as another very reliable sign of ALCAPA. ${ }^{5}$

The haemodynamic features of isolated ALCAPA depend on the ability of a collateral circulation to develop. They change with age. Several different haemodynamic stages have been described: embryonic, collateral, fistula, and finally coronary steal. ${ }^{1}$ Angiography in assessment showed five common forms of intercoronary collaterals. ${ }^{6}$ One form showed retrograde filling of the left coronary artery via septal branches of the right coronary artery to the left anterior descending artery.

We believe that colour flow mapping of intercoronary collateral flow has not been described before in patients with ALCAPA. We are aware that all the Doppler signs that are typical of ALCAPA are related to collateral flow from the right coronary artery and if the collateral vessels are poorly developed the signs may not be present. None the less, the detection of intercoronary collateral flow is a further useful echocardiographic pointer to the diagnosis of this serious congenital anomaly.

1 Neufeld HN, Schneeweiss A. Anomalous origin of the coronary arteries from the pulmonary artery. In: Neufeld HN, Schneeweiss A, eds. Coronary artery disease in infants and children. Philadelphia: Lea and Febiger, in infants and

2 Schmidt KG, Cooper MJ, Silverman, NH, Stanger P. Pulmonary artery origin of the left coronary artery Diagnosis by two-dimensional echocardiography, pulsed Doppler ultrasound and color flow mapping. $尹 A C C$ 1988;11:396-402.

3 Holley DG, Sell JE, Hougen TJ, Martin GR. Pulsed Doppler echocardiographic and color flow imaging detection of retrograde filling of anomalous left coronary artery from the pulmonary artery. $\mathcal{F} \mathrm{Am}$ Soc Echocardiogr 1992;5:85-8.

4 Jureidini SB, Nouri S, Crawford CJ, Chen S, Pennington DP, Fiore A. Reliability of echocardiography in the diagnosis of anomalous origin of the left coronary artery from the pulmonary trunk. Am Heart $\mathcal{F} 1991 ; 122: 61-8$.

5 Karr SS, Parness IA, Spevak PJ, van der Elde ME, Colan SD, Sanders SS. Diagnosis of anomalous left coronary artery by Doppler color flow mapping. Distinction from other causes of dilated cardiomyopathy. $₹ \mathrm{Am}$ Coll Cardiol 1992;19:1271-5.

6 Hawker RE, Bowdler JD, Celermajer EM, Johnson DC, Cartmill BB. Angiographic assessment of anomalous origin of the left coronary from the pulmonary artery in infancy and childhood. Pediatr Radiol 1976;5:69-74. 